\title{
Association of IL-17A and IL-17F Gene Polymorphisms with Acute Immune Thrombocytopenia in Egyptian Children
}

\author{
Shereen Philip Aziz'1, Heba A. Ahmed', Ramadan A. Mahmoud2², Marwa Ahmed Mahmoud ${ }^{3}$ \\ ${ }^{1}$ Department of Clinical Pathology, Faculty of Medicine, Sohag University, Sohag, Egypt \\ ${ }^{2}$ Department of Pediatrics, Faculty of Medicine, Sohag University, Sohag, Egypt \\ ${ }^{3}$ Department of Physiology, Faculty of Medicine, Sohag University, Sohag, Egypt \\ Email: ^ramadan.aboelhassan@yahoo.com
}

How to cite this paper: Aziz, S.P., Ahmed, H.A., Mahmoud, R.A. and Mahmoud, M.A. (2018) Association of IL-17A and IL-17F Gene Polymorphisms with Acute Immune Thrombocytopenia in Egyptian Children. Open Journal of Blood Diseases, 8, 49-60. https://doi.org/10.4236/ojbd.2018.83006

Received: September 5, 2018

Accepted: September 18, 2018

Published: September 21, 2018

Copyright $\odot 2018$ by authors and Scientific Research Publishing Inc. This work is licensed under the Creative Commons Attribution International License (CC BY 4.0).

http://creativecommons.org/licenses/by/4.0/ Open Access

\begin{abstract}
Background: IL-17 is an inflammatory cytokine that plays a crucial role in many autoimmune diseases. Aim: To investigate the association of IL-17A rs2275913 and IL-17F rs763780 gene polymorphisms with acute immune thrombocytopenic purpura (ITP) in Egyptian children. Patients and methods: We examined 80 patients (male/female, 33/47; median age, 7 years old) diagnosed with acute ITP and 55 healthy controls (male/female, 28/27; median age, 7 years old). Genotyping was determined using the polymerase chain reaction-restriction fragment length polymorphism (PCR-RFLP) technique. Results: In the acute ITP group compared to control, statistical analysis of the genotype frequencies (GG, AG, AA) of the IL-17A rs2275913 polymorphism and its alleles $(A, G)$ showed no significant difference between the two groups $(p>0.05)$. Interestingly, the IL17A rs2275913 GG genotype was associated with early recovery $(p=0.04)$. As regard the genotype frequencies of the IL-17F rs763780 polymorphism, there was statistical significant difference in the TT and TC genotype frequencies between the case and control groups ( $p$ $=0.001$ and $p=0.003$, respectively). The number of IL-17F rs763780 T alleles was significantly higher in acute ITP patients as compared with children in the control group $(p<0.001)$. Conclusion: The present findings indicate that the IL-17 polymorphism IL-17F rs763780, but not IL-17A rs2275913 may be associated with a higher risk of acute ITP in Egyptian children.
\end{abstract}

\section{Keywords}

Acute Immune Thrombocytopenia, IL-17F, IL-17A, Polymorphism, Genotyping 


\section{Introduction}

Acute immune thrombocytopenia (ITP) is a disorder characterized by immune-mediated accelerated platelet destruction and suppressed platelet production [1]. Childhood acute ITP is a common pediatric hematological disorder involving thrombocytopenia with normal to increased megakaryocytes in the bone marrow [2]. The development of autoantibodies by B cells remains the central cause of ITP pathophysiology; however, multi-dysfunction in cellular immunity and cytokine response may also play a role in the pathogenesis of the disease [3]. Nevertheless, both $\mathrm{T}$ and $\mathrm{B}$ lymphocytes, antibodies, cytokines, antigen-presenting cells, and co-stimulatory molecules are involved in the immune response [4].

Investigations have shown upregulated interleukin (IL)-17-producing CD4+ T cells (Th17) in patients with acute ITP [4]. The balance between T-helper type 1 (Th1) and type 2 (Th2) cells has been implicated in the regulation of the immune response in many diseases, with a high Th1:Th2 ratio being reported in patients with acute ITP [5]. An imbalance in the Th1:Th2 ratio is inversely correlated with the severity of acute ITP [6]. Moreover, the IL-17 cytokine induces the production of pro-inflammatory cytokines, chemokines, cell adhesion molecules, growth factors [7], and enhanced expression of IL-17 has been shown in patients with other autoimmune disorders such as asthma [8], ulcerative colitis [9], and rheumatoid arthritis [10].

The IL-17 family is composed of several closely-related cytokines including IL-17A-F and five receptors (IL-17RA-E) [11]. The genes for two widely studied members of the family, IL-17A and IL-17F, are located at 6p12. These two cytokines show high sequence similarity, possess similar receptor specificity, and are responsible for the pathogenic activity of Th17 cells [12]. IL-17A rs2275913, also known as G-197A, is a single nucleotide polymorphism (SNP) positioned within a binding motif for the nuclear factor of activated T cells (NFAT), a critical regulator of IL-17 expression; therefore, this SNP may affect the transcriptional regulation of IL-17 [13]. Moreover, IL-17F 7488 T/C (rs763780) is another polymorphism that is located within the coding region of IL-17F and causes the His-to-Arg substitution at amino acid 161 [7]. There were only small numbers of Egyptian and other international researches highlighted the genetic pattern of acute ITP in children.

Therefore, the main aim of this study to evaluate the impact of IL17 polymorphisms on the susceptibility and clinical features of childhood acute ITP, we analyzed the allelic and genotypic frequencies of IL17F and IL17A gene polymorphisms in Egyptian children with acute ITP and healthy controls.

\section{Materials and Methods}

The present study included 80 newly diagnosed acute ITP patients attending the Pediatric Hematology Unit in the Department of Pediatrics, Sohag University, Egypt, between February 2016 and March 2018, and 55 healthy controls (they had complete normal examinations, no previous history of ITP, CBC were col- 
lected from these children in the outpatient clinic during routinely visits).

An acute ITP diagnosis was made on the basis of history, a detailed physical examination, and tests for the presence of thrombocytopenia $\left(<100 \times 10^{9} / \mathrm{L}\right)$ with otherwise normal red cells and leukocytes and the exclusion of other causes by examination of a peripheral blood (PB) smear [14]. Bone marrow aspiration was performed to rule out other diseases with increased marrow megakaryocytes. Exclusion criteria were infants aged $<6$ months, manifestations of active infection, splenomegaly, and secondary causes of ITP such as systemic lupus erythematosus (SLE).

A complete blood count (CBC) using a Cell-Dyn 3700 automated cell counter, (ABBOTT diagnostic, USA) and examination of Leishman-stained PB smears were carried out. Newly diagnosed acute ITP patients received a treatment protocol in the form of corticosteroids; a course of $2 \mathrm{mg} / \mathrm{kg} /$ day prednisone for 2 weeks, and tapered over 21 days according to Provan et al. [15]. We followed up the patients for 3 months to detect remission or progression to the persistent course of the disease. Local ethical approval for the present study was obtained from the Research Committee of the Faculty of Medicine at Sohag University, Egypt, and written informed consent was obtained from all parents of the patients.

\subsection{Genetic Analysis}

The polymorphisms of IL-17A rs2275913 and IL-F rs763780 were detected by the polymerase chain reaction-restriction fragment length polymorphism (PCR-RFLP) technique. DNA was extracted from whole blood samples with EDTA using a Quick-gDNA ${ }^{\mathrm{TM}}$ MiniPrepkit (Catalog No.D3025) according to the manufacturer's instructions. For SNP rs2275913, the following primers were used; forward 5'-TCT CCA TCT CCA TCA CCT TTG-3'and reverse 5'-GTC CAA ATC AGC AAG AGC ATC-3'. For SNP rs763780, the following primers were used; forward 5'-CAC TGG TGC TCT GAT GAG GA-3' and reverse 5'-CATTGT GCT TTG GCT TGC T-3'.

Each PCR reaction was performed in a $25 \mu \mathrm{l}$ tube containing $3 \mu \mathrm{l}$ DNA, $12.5 \mu \mathrm{l}$ master mix (Ampliqon, Denmark), $7 \mu$ distilled water, and $1.25 \mu \mathrm{l}$ each primer. The PCR cycling conditions for IL-17A (rs2275913) consisted of an initial denaturation at $94^{\circ} \mathrm{C}$ for $5 \mathrm{~min}$, followed by 30 cycles of denaturation for $1 \mathrm{~min}$ at $94^{\circ} \mathrm{C}$, annealing for $1 \mathrm{~min}$ at $57^{\circ} \mathrm{C}$, and extension for $1 \mathrm{~min}$ at $72^{\circ} \mathrm{C}$. A final extension was carried out for $5 \mathrm{~min}$ at $72^{\circ} \mathrm{C}$. The PCR products were subjected to electrophoresis on a $2 \%$ agarose gel at $130 \mathrm{~V}$ for $30 \mathrm{~min}$. Subsequently, the PCR product was digested by the restriction enzyme, EcoNI (XagI) (\#ER1301) according to kit instructions (Thermo Scientific). The PCR cycling conditions for IL-17F (rs763780) consisted of an initial denaturation at $94^{\circ} \mathrm{C}$ for $5 \mathrm{~min}$, followed by 30 cycles of denaturation for $1 \mathrm{~min}$ at $94^{\circ} \mathrm{C}$, annealing for $1 \mathrm{~min}$ at $53^{\circ} \mathrm{C}$, and extension for $1 \mathrm{~min}$ at $72^{\circ} \mathrm{C}$. A final extension was carried out for 5 min at $7^{\circ} \mathrm{C}$. Following gel electrophoresis, the PCR product was digested by the restriction enzyme, Nla III (Hin1II) (\#ER1831) according to kit instructions 
(Thermo Scientific).

The patterns were observed following digestion and electrophoresis: the undigested PCR product size was $815 \mathrm{bp}$ for SNP rs2275913, and restriction digestion for the GG genotype generated 259, 270, and 286 bp fragments; whereas the AG genotype generated 259, 270, 286, and $529 \mathrm{bp}$, and the AA genotype generated 286 and $529 \mathrm{bp}$ fragments; the undigested PCR product size was $635 \mathrm{bp}$ for SNP rs763780, and the TT genotype generated 124,130, and381 bp fragments, whereas the TC genotype generated 124, 130, 381, and $511 \mathrm{bp}$ fragments, and the CC genotype generated 124 and $511 \mathrm{bp}$ fragments.

\subsection{Statistical Analysis}

Data was analyzed using the SPSS version 25.0 software. Allele and genotype frequencies were calculated by direct counting. Quantitative data are expressed as the mean \pm standard deviation, median, and range; and qualitative data, as numbers and percentages. The data were tested for normality using the Shapiro-Wilk test. The non-parametric Kruskal Wallis, Mann-Whitney, and Wilcoxon Signed Ranks tests were used for data that was not normally distributed; and an independent sample $t$-test was used for normally distributed data. Chi-square $(\chi 2)$ and Fisher's exact tests were used for comparison of the genotype and allele frequencies of IL-17 regarding qualitative variables, as appropriate. The odds ratio (OR) and 95\% confidence interval (CI) were calculated using logistic regression. Binary logistic regression tests were used to study the association of the genotypes and ITP occurrence with outcome among the studied patients. A $p$-value $<0.05$ was considered significant in all statistical tests used in the present study.

\section{Results}

Eighty newly diagnosed acute ITP patients (male/female, 33/47; median age, 7 years old; range 2 - 14 years old) attending our the Pediatric Hematology Unit and 55 healthy controls (male/female, 28/27; median age, 7 years old; range 3 13 years old), were included in the present study.

In this study, the platelet count ranged from $7 \times 10^{9} / \mathrm{L}$ to $82.3 \times 10^{9} / \mathrm{L}$, with a mean platelet count of $27.19 \times 10^{9} / \mathrm{L}$ at initial diagnosis. Moreover, 25 (31.25\%) patients had very severe thrombocytopenia (platelet count $<10 \times 10^{9} / \mathrm{L}$ ); 34 (42.5\%) patients had severe ITP (platelet count $\left.10 \times 10^{9}-30 \times 10^{9} / \mathrm{L}\right) ; 12(15 \%)$ patients had moderates thrombocytopenia (platelet count: $30 \times 10^{9}-50 \times 10^{9} / \mathrm{L}$ ), $9(11.25 \%)$ patients had mild thrombocytopenia (platelet count $>50 \times 10^{9} / \mathrm{L}$ ). As regard the presenting symptoms, 22 (27.5\%) had mild bruising at diagnosis; 48 (60\%) presented with purpura and mild mucocutaneous bleeding; and 10 (12.5\%) with clinically significant symptoms of bleeding at diagnosis. Moreover, no cases reported with intracranial hemorrhage.

The genotype and allele frequencies of IL-17F and IL17A in the patients with acute ITP are summarized in Table 1 . Patients with acute ITP had a significantly 
Table 1. Genotype distribution and allele frequency of IL-17F and IL-17A gene polymorphism in patients with ITP and healthy control.

\begin{tabular}{cccccc}
\hline Genotyping & $\begin{array}{c}\text { ITP } \\
(\mathrm{n}=80)\end{array}$ & $\begin{array}{c}\text { Control } \\
(\mathrm{n}=55)\end{array}$ & OR & CI 95\% & $P$ value \\
\hline IL-17F & & & & & \\
TT & $52(65 \%)$ & $19(34.5 \%)$ & 3.52 & $1.71-7.24$ & $0.001^{*}$ \\
TC & $26(32.5 \%)$ & $32(58.2 \%)$ & 0.35 & $0.17-0.71$ & $0.003^{*}$ \\
CC & $2(2.5 \%)$ & $4(7.3 \%)$ & 0.3 & $0.06-1.85$ & 0.206 \\
IL17A & & & & & \\
AA & $42(52.5 \%)$ & $30(54.6 \%)$ & 0.92 & $0.46-1.83$ & 0.815 \\
AG & $30(37.5 \%)$ & $23(41.8 \%)$ & 0.84 & $0.41-1.68$ & 0.614 \\
GG & $8(10 \%)$ & $2(3.6 \%)$ & 2.94 & $0.6-14.43$ & 0.183 \\
T alleles & $130(81.3 \%)$ & $70(63.6 \%)$ & 2.48 & $1.42-4.32$ & $0.001^{*}$ \\
C alleles & $30(18.6 \%)$ & $40(36.4 \%)$ & 0.4 & $0.23-0.7$ & $0.001^{*}$ \\
A alleles & $114(71.3 \%)$ & $83(75.5 \%)$ & 0.81 & $0.46-1.4$ & 0.45 \\
G alleles & $46(28.7 \%)$ & $27(24.5 \%)$ & 1.24 & $0.71-2.16$ & 0.445 \\
\hline
\end{tabular}

higher frequency of the IL-17F rs763780 TT genotype as compared with children in the control group (65\% vs. $34.5 \%, p<0.001)$, and had a significantly lower frequency of the IL-17F rs763780TC genotype ( $32.5 \%$ vs. $58.2 \%, p=0.003$ ).

Furthermore, in the case group, the genotype frequencies of the IL-17A rs2275913 polymorphism were GG (10\%), AG (37.5\%), and AA (52.5\%), and in the control group, GG (3.6\%), AG (41.8\%), and AA (54.5\%). Comparison between the case and control populations with respect to the three genotypes revealed no statistically significant difference.

The number of IL-17F rs763780T alleles was significantly higher in the acute ITP patients as compared with the children in the control group $(81.6 \%$ vs. $63.6 \% \mathrm{OR}=2.48,95 \% \mathrm{CI}=1.42-4.32, p<0.001)$. Moreover, the number of IL-17F rs763780 C alleles among the patients with ITP was also significantly lower than among the children in the control group $(18.6 \%$ vs. $36.4 \% \mathrm{OR}=0.4$, $95 \% \mathrm{CI}=0.23-0.7, p<0.001$ ).

As shown in Table 1, the frequency of allele A of IL17A rs2275913 was 71.3\% in the case group and $75.5 \%$ in the control group, which not significantly different $(p=0.45)$ between the two groups. Similarly, the frequency of allele $\mathrm{G}$ was $28.7 \%$ in the case group and $24.5 \%$ in the control group, the difference between which was also not significant $(p=0.445)$.

We investigated the association of the IL-17F and IL17A genotypes with the clinical features of acute ITP (Tables 2-4). There was no significant association between the frequencies of the genotypes and the various clinical features, including gender, age, disease severity of ITP, or the outcome following treatment; with the exception of the IL17A rs2275913 GG genotype being more closely associated with early recovery than with a persistent course of the disease $(21.7 \%$ vs. $5.3 \%, p=0.04)$. 
Table 2. Relation between outcome of ITP and IL17A and IL 17F genotypes.

\begin{tabular}{|c|c|c|c|}
\hline Genes & $\begin{array}{l}\text { Recovery ITP within } 3 \text { months } \\
\qquad(\mathrm{N}=23)\end{array}$ & $\begin{array}{l}\text { Persistent ITP more than } 3 \text { months } \\
\qquad(\mathrm{N}=57)\end{array}$ & $p$-value \\
\hline \multicolumn{4}{|l|}{ AA } \\
\hline No & $12(52.2 \%)$ & $26(45.6 \%)$ & 0.595 \\
\hline Yes & $11(47.8 \%)$ & $31(54.4 \%)$ & \\
\hline \multicolumn{4}{|l|}{ AG } \\
\hline No & $16(69.6 \%)$ & $34(59.6 \%)$ & 0.407 \\
\hline Yes & $7(30.4 \%)$ & $23(40.4 \%)$ & \\
\hline \multicolumn{4}{|l|}{ GG } \\
\hline No & $18(78.3 \%)$ & $54(94.7 \%)$ & $0.04^{*}$ \\
\hline Yes & $5(21.7 \%)$ & $3(5.3 \%)$ & \\
\hline \multicolumn{4}{|l|}{$\mathrm{CC}$} \\
\hline No & $23(100 \%)$ & $55(96.5 \%)$ & $0.505^{\star}$ \\
\hline Yes & $0(0.0 \%)$ & $2(3.5 \%)$ & \\
\hline \multicolumn{4}{|l|}{$\mathrm{TC}$} \\
\hline No & 17 (73.9\%) & 37 (64.9\%) & 0.437 \\
\hline Yes & $6(26.1 \%)$ & $20(35.1 \%)$ & \\
\hline \multicolumn{4}{|l|}{$\mathrm{TT}$} \\
\hline No & $6(26.1 \%)$ & $22(38.6 \%)$ & 0.288 \\
\hline Yes & $17(73.9 \%)$ & $35(61.4 \%)$ & \\
\hline
\end{tabular}

Table 3. Relation between age, gender and severity of thrombocytopenia with IL17A.

\begin{tabular}{|c|c|c|c|c|}
\hline \multirow[b]{2}{*}{ Genes } & \multicolumn{3}{|c|}{ IL17A } & \multirow[b]{2}{*}{$p$-value } \\
\hline & $\begin{array}{c}\text { AA } \\
(\mathrm{N} .=42)\end{array}$ & $\begin{array}{c}\text { AG } \\
(\mathrm{N} .=30)\end{array}$ & $\begin{array}{c}\text { GG } \\
(\mathrm{N} .=8)\end{array}$ & \\
\hline \multicolumn{5}{|l|}{ Age } \\
\hline $\begin{array}{c}\text { Mean } \pm \text { S.D. } \\
\text { Median (Range) }\end{array}$ & $\begin{array}{c}7.38 \pm 3.08 \\
7(2-13)\end{array}$ & $\begin{array}{l}6.82 \pm 2.66 \\
6.3(2-12)\end{array}$ & $\begin{array}{l}7.56 \pm 3.34 \\
6.5(4-13)\end{array}$ & $0.6^{*}$ \\
\hline \multicolumn{5}{|l|}{ Sex } \\
\hline $\begin{array}{l}\text { Female } \\
\text { Male }\end{array}$ & $\begin{array}{l}26(61.9 \%) \\
16(38.1 \%)\end{array}$ & $\begin{array}{l}18(60 \%) \\
12(40 \%)\end{array}$ & $\begin{array}{l}3(37.5 \%) \\
5(62.5 \%)\end{array}$ & 0.431 \\
\hline \multicolumn{5}{|l|}{ Thrombocytopenia } \\
\hline Mild & $4(9.5 \%)$ & $2(6.7 \%)$ & $3(37.5 \%)$ & \multirow{4}{*}{0.34} \\
\hline Moderate & $6(14.3 \%)$ & $6(20 \%)$ & $0(0 \%)$ & \\
\hline Severe & $18(42.9 \%)$ & $13(43.3 \%)$ & $3(37.5 \%)$ & \\
\hline Very severe & $14(33.3 \%)$ & $9(30 \%)$ & $2(25 \%)$ & \\
\hline
\end{tabular}


Table 4. Relation between age, gender and severity of thrombocytopenia with IL17F.

\begin{tabular}{ccccc}
\hline & \multicolumn{3}{c}{ IL17 F } & \multirow{2}{*}{$p$-value } \\
\cline { 2 - 4 } Genes & $\begin{array}{c}\text { CC } \\
(\mathrm{N} .=2)\end{array}$ & $\begin{array}{c}\text { TC } \\
(\mathrm{N} .=26)\end{array}$ & $\begin{array}{c}\text { TT } \\
(\mathrm{N} .=52)\end{array}$ & \\
\hline Age & & & 0.199 \\
Mean \pm S.D. & $3.75 \pm 1.06$ & $7.33 \pm 2.73$ & $7.25 \pm 3.04$ & \\
Median (Range) & $3.75(3-4.5)$ & $7(2-12)$ & $7(2-13)$ & 0.918 \\
Sex & & & & \\
Female & $1(50 \%)$ & $16(61.5 \%)$ & $30(57.7 \%)$ & \\
Male & $1(50 \%)$ & $10(38.5 \%)$ & $22(42.3 \%)$ & \\
Thrombocytopenia & & & $6(11.5 \%)$ & \\
Mild & $0(0.0 \%)$ & $3(11.5 \%)$ & $9(17.4 \%)$ & \\
Moderate & $0(0.0 \%)$ & $3(11.5 \%)$ & $19(36.5 \%)$ & 0.336 \\
Severe & $1(50 \%)$ & $14(53.8 \%)$ & $18(34.6 \%)$ & \\
Very severe & $1(50 \%)$ & $6(23.2 \%)$ & & \\
\hline
\end{tabular}

\section{Discussion}

Immune thrombocytopenic purpura (ITP) is a highly complex autoimmune disease. Approximately $80 \%$ of ITP patients present with an acute course [16], hence, the initial pathogenic mechanisms underlying primary ITP are not yet understood. Both B and T cells play a crucial role in acute ITP. Abnormal T cell subsets including lower levels of T-regulatory cells (Tregs), unbalanced Th17, Th0, and Th1 profiles, and the presence of cytotoxic CD8+ T cells constitute the cellular mechanisms of ITP pathogenesis [17]. This pathogenesis is enhanced by increased levels of the pro-inflammatory cytokines IFN- $\gamma$, IL-2, and IL-17, and decreased levels of the immunosuppressive cytokines IL-10, TGF- $\beta$, and IL-4, enhancing autoantibody development. Underlying these defects is a deficiency in immune tolerance due to defects in both Tregs and B regulatory cells (Bregs) [18] [19]. Liu et al. [20] reported that Th17 cells and their associated cytokines, IL- 6 and TGF- $\beta$, are significantly upregulated in patients with ITP, which may, in association with Treg impairment, promote a Th1-mediated immune response and trigger the disease in both humans and mice [21] [22].

Moreover, El Husseiny et al. [23] found that IL-17 levels increased with increased Th17 cells in patients with acute ITP, which is in accordance with other studies [24] [25], and IL-17 has been shown to be down regulated following immunosuppressive therapy [25]. Furthermore, Okamoto et al. [26] demonstrated that the response to Eltrombopag, a drug used for thrombocytopenia, is significantly better in patients with low IL-17 expression, indicating that patients with ITP who achieve early remission may have low IL-17 levels [26]. Thus, extensive genetic research has highlighted the importance of the IL-17 gene, which may help to elucidate the biology of ITP and suggest novel disease biomarkers or 
targets for therapy [27] [28].

The present study interrogated the association of the rs763780 and rs2275913 SNPs in the IL-17 gene with acute ITP in Egyptian children, and found that the IL-17F rs763780 T allele was significantly associated with an increased risk of ITP. However, the IL-17F rs763780 C allele was significantly associated with a decreased risk of ITP. Patients with acute ITP had a significantly higher frequency of the IL-17F rs763780 TT genotype as compared with children in the control group, and also had a significantly lower frequency of the IL-17F rs763780 TC genotype. The difference in the frequency of alleles A and G in IL-17A rs2275913 between the two groups was not significant.

These results are consistent with Saitoh et al. [29] who studied 102 Japanese patients for the IL17F polymorphism and suggested that the IL-17F T allele is significantly associated with the development of chronic ITP. Furthermore, Liu et al. [30] studied 146 Chinese chronic ITP patients and 137 healthy controls for IL-17A G197A and IL-17F A7488G polymorphisms, and found no significant difference in the frequencies of the IL-17A G197A genotypes and alleles between ITP patients and healthy controls, whereas the frequency of IL-17F T7488C allele A was significantly higher in ITP patients than in healthy controls. It was also found that patients with ITP had significantly higher frequencies of the IL-17F T7488CTT and TC genotypes as compared with healthy controls. These data differ from our results, in which we found that only the IL-17F TT genotype was significantly higher in acute ITP patients as compared with children in the control group. These results could be attributed to the ethnic difference between the studied populations.

An Egyptian study was carried out by Mokhtar et al. [27] aiming to investigate the possible association between ITP development in childhood and several genetic polymorphisms including IL-17F. They found a significantly higher incidence of mutant IL-17F genotypes $(p=0.0001)$ was found among the ITP patients as compared with the individuals in the control group. However, another study by Yousry et al. [31] is in accordance with the present study, since it was found that Egyptian chronic ITP patients have a significantly higher frequency of the IL-17F TT genotype as compared with control individuals (84.1\% versus $70.0 \% ; \mathrm{OR}=2.269 ; p=0.015)$. Furthermore, in contrast to the present results, Botros et al. [32] in another Egyptian study examining a small sample of 50 children with ITP (mean age of 7 years old) together with 50 age-and gender-matched healthy control children, showed that the IL-17F gene polymorphism at rs7488T/C likely does not contribute to the susceptibility to ITP development in Egyptian children.

Several polymorphism studies have shown an association between IL-17F and other immunological disorders. The IL-17F 7488CC genotype (mutant Arg161) has been shown to affect asthma susceptibility, being associated with a decreased risk of certain types of asthma. [8] The IL-17F gene has been demonstrated to play a role in ulcerative colitis [9], rheumatoid arthritis [10] [33], and recurrent 
pregnancy loss [34]. A Polish study in patients with rheumatoid arthritis showed that the AA genotype frequency of IL-17F rs763780 may be associated with increased disease activity [10].

With respect to the outcome of acute ITP, Saitoh et al. [29] found that patients with the IL-17F 7488TT genotype showed a more severe thrombocytopenic state (platelet count $<10 \times 10^{9} / \mathrm{L}$ ) at diagnosis than those with the IL-17F 7488TC genotype (20.9\% versus $0 \%, p=0.04)$. Moreover, Yousry et al. [31] found that the IL17F TT genotype is significantly associated with a poor response to steroid therapy ( $11.1 \%$ were steroid responsive versus $88.9 \%$ unresponsive; $p=0.001$ ). These data are inconsistent with the present results, in which we found no significant association between the frequencies of the IL-17F and IL-17A genotypes and various clinical features including gender, age, ITP severity or case outcome following treatment. However, we did find that the IL-17A rs2275913 GG genotype was more often associated with recovery than with persistent ITP. This can be attributed to the lower frequency of the GG genotype in both the patient and control groups in the present work (5 (21.7\%) vs. $3(5.3 \%), p=$ $0.04)$; nevertheless, studies with larger cohorts are recommended to verify these data.

There were some limitations in this study which could affect the results. First, it was a single-centre study. Second, the numbers of patients may not be large enough which weakness our ability to solidity statistical association. Further studies with a larger sample size in different population are needed to identify the association between IL-17F and IL-17A gene polymorphisms in acute and chronic ITP patients. Finally, only two IL17 polymorphisms were tested in the case and control group; however they were the most common gene polymorphism present in ITP patients.

\section{Conclusion}

The present results suggest that the IL-17F rs763780 $\mathrm{T}$ allele was significantly associated with an increased risk of ITP, while the IL-17F rs763780 C allele was significantly associated with a decreased risk of ITP. Conversely, we found no significant association between IL-17A rs2275913 and the risk of ITP in Egyptian children.

\section{Acknowledgements}

The authors would like to thank Proof-Reading-Services.com for language editing.

\section{Conflicts of Interest}

The authors have no conflicts of interest.

\section{Funding}

The authors received no funding to perform the present study. 


\section{References}

[1] Ballem, P., Segal, G., Stratton, J., et al. (1987) Mechanisms of Thrombocytopenia in Chronic Autoimmune Thrombocytopenic Purpura. Evidence of Both Impaired Platelet Production and Increased Platelet Clearance. The Journal of Clinical Investigation, 80, 33-40. https://doi.org/10.1172/JCI113060

[2] Akin, M., Turgut, S., Ayada, C., et al. (2011) Relation between 3435C T Multidrug Resistance 1 Gene Polymorphism with High Dose Methylprednisolone Treatment of Childhood Acute Idiopathic Thrombocytopenic Purpura. Gene, 487, 80-83. https://doi.org/10.1016/j.gene.2011.06.019

[3] Stasi, R., Evangelista, M., Stipa, E., et al. (2008) Idiopathic Thrombocytopenic Purpura: Current Concepts in Pathophysiology and Management. Journal of Thrombosis and Haemostasis, 99, 4-13.

[4] Zhang, J., Ma, D., Zhu, X., et al. (2009) Elevated Profile of Th17, Th1 and Tc1 Cells in Patients with Immune Thrombocytopenic Purpura. Haematologica, 94, 1326-1329. https://doi.org/10.3324/haematol.2009.007823

[5] Ogawara, H., Handa, H., Morita, K., et al. (2003) High Th1/Th2 Ratio in Patients with Chronic Idiopathic Thrombocytopenic Purpura. European Journal of Haematology, 71, 283-288. https://doi.org/10.1034/j.1600-0609.2003.00138.x

[6] Panitsas, F.P., Theodoropoulou, M., Kouraklis, A., et al. (2004) Adult Chronic Idiopathic Thrombocytopenic Purpura (ITP) Is the Manifestation of a Type-1 Polarized Immune Response. Blood, 103, 2645-2647.

https://doi.org/10.1182/blood-2003-07-2268

[7] Kawaguchi, M., Takahashi, D., Hizawa, N., et al. (2006) IL-17F Sequence Variant (His161Arg) Is Associated with Protection against Asthma and Antagonizes Wild-Type IL-17F Activity. Journal of Allergy and Clinical Immunology, 117, 795-801. https://doi.org/10.1016/j.jaci.2005.12.1346

[8] Kawaguchi, M., Kokubu, F., Fujita, J., et al. (2009) Role of Interleukin-17F in Asthma. Inflammation \& Allergy-Drug Targets, 8, 383-389. https://doi.org/10.2174/1871528110908050383

[9] Arisawa, T., Tahara, T., Shibata, T., et al. (2008) The Influence of Polymorphisms of Interleukin-17A and Interleukin-17F Genes on the Susceptibility to Ulcerative Colitis. Journal of Clinical Immunology, 28, 44-49. https://doi.org/10.1007/s10875-007-9125-8

[10] Paradowska-Gorycka, A., Wojtecka-Lukasik, E., Trefler, J., et al. (2010) Association between IL-17F Gene Polymorphisms and Susceptibility to and Severity of Rheumatoid Arthritis (RA). Scandinavian Journal of Immunology, 72, 134-141. https://doi.org/10.1111/j.1365-3083.2010.02411.x

[11] Kaabachi, W., Ben Amor, A., Kaabachi, S., et al. (2014) Interleukin-17A and -17F Genes Polymorphisms in Lung Cancer. Cytokine, 66, 23-29. https://doi.org/10.1016/j.cyto.2013.12.012

[12] Reynolds, J.M., Angkasekwinai, P. and Dong, C. (2010) IL-17 Family Member Cytokines: Regulation and Function in Innate Immunity. Cytokine \& Growth Factor Reviews, 21, 413-423. https://doi.org/10.1016/j.cytogfr.2010.10.002

[13] Liu, X.K., Lin, X. and Gaffen, S.L. (2004) Crucial Role for Nuclear Factor of Activated T Cells in T Cell Receptor-Mediated Regulation of Human Interleukin-17. Journal of Biological Chemistry, 279, 52762-52771. https://doi.org/10.1074/jbc.M405764200

[14] George, J.N., Woolf, S.H., Raskob, G.E., et al. (1996) Idiopathic Thrombocytopenic 
Purpura: A Practice Guideline Developed by Explicit Methods for the American Society of Hematology. Blood, 88, 3-40.

[15] Provan, D., Stasi, R., Newland, A.C., et al. (2010) International Consensus Report on the Investigation and Management of Primary Immune Thrombocytopenia. Blood, 115, 168-186. https://doi.org/10.1182/blood-2009-06-225565

[16] Johnsen, J. (2012) Pathogenesis in Immune Thrombocytopenia: New Insights. Hematology ASH Education Program, 2012, 306-312.

[17] Zufferey, A., Kapur, R. and Semple, J.W. (2017) Pathogenesis and Therapeutic Mechanisms in Immune Thrombocytopenia (ITP). Journal of Clinical Medicine, 6, 16. https://doi.org/10.3390/jcm6020016

[18] Stasi, R., Bosworth, J., Rhodes, E., et al. (2010) Thrombopoietic Agents. Blood Reviews, 24, 179-190. https://doi.org/10.1016/j.blre.2010.04.002

[19] Ji, L., Zhan, Y., Hua, F., et al. (2012) The Ratio of Treg/Th17 Cells Correlates with the Disease Activity of Primary Immune Thrombocytopenia. PLoS ONE, 7, e50909. https://doi.org/10.1371/journal.pone.0050909

[20] Liu, L., Zhang, X., Zhao, G., et al. (2012) Change of Th22 Cells in Peripheral Blood of Patients with Primary Immune Thrombocytopenia and Clinical Implication. Chinese Journal of Cellular and Molecular Immunology, 28, 1314-1316.

[21] Hu, Y., Ma, D.-X., Shan, N.-N., et al. (2011) Increased Number of Tc17 and Correlation with Th17 Cells in Patients with Immune Thrombocytopenia. PLoS ONE, 6, e26522. https://doi.org/10.1371/journal.pone.0026522

[22] Baeten, D.L. and Kuchroo, V.K. (2013) How Cytokine Networks Fuel Inflammation: Interleukin-17 and a Tale of Two Autoimmune Diseases. Nature Medicine, 19, 824. https://doi.org/10.1038/nm.3268

[23] El Husseiny, N.M., El Sobky, A., Khalaf, A.M., et al. (2018) Immune Thrombocytopenia. Egyptian Experience with Study of IL-17, TGFB, Cytokines in Chronic and Persistent Immune Thrombocytopenia Patients. International Journal of Advanced Research, 6, 1087-1090. https://doi.org/10.21474/IJAR01/6770

[24] Ye, X., Zhang, L., Wang, H., et al. (2015) The Role of IL-23/Th17 Pathway in Patients with Primary Immune Thrombocytopenia. PLoS ONE, 10, e0117704. https://doi.org/10.1371/journal.pone.0117704

[25] Li, W., Wang, X., Li, J., et al. (2016) A Study of Immunocyte Subsets and Serum Cytokine Profiles before and after Immunal Suppression Treatment in Patients with Immune Thrombocytopenia. Chinese Journal of Internal Medicine, 55, 111-115.

[26] Okamoto, N., Homma, M., Kawaguchi, Y., et al. (2017) Differential Expression of IL-17 Correlates with Clinical and Pathological Features of ITP. Blood, 130, 3644.

[27] Mokhtar, G.M., El-beblawy, N.M., Adly, A.A., et al. (2016) Cytokine Gene Polymorphism [Tumor Necrosis Factor-Alpha (-308), IL-10 (-1082), IL-6 (-174), IL-17F, 1RaVNTR] in Pediatric Patients with Primary Immune Thrombocytopenia and Response to Different Treatment Modalities. Blood Coagulation \& Fibrinolysis, 27, 313-323. https://doi.org/10.1097/MBC.0000000000000431

[28] McKenzie, C.G., Guo, L., Freedman, J., et al. (2013) Cellular Immune Dysfunction in Immune Thrombocytopenia (ITP). British Journal of Haematology, 163, 10-23. https://doi.org/10.1111/bjh.12480

[29] Saitoh, T., Tsukamoto, N., Koiso, H., et al. (2011) Interleukin-17F Gene Polymorphism in Patients with Chronic Immune Thrombocytopenia. European Journal of Haematology, 87, 253-258. https://doi.org/10.1111/j.1600-0609.2011.01651.x

[30] Liu, S., Xiong, Y.-Z., Li, T., et al. (2016) Interleukin-17A and -17F Gene Polymor- 
phisms in Chinese Population with Chronic Immune Thrombocytopenia. Annals of Clinical \& Laboratory Science, 46, 291-297.

[31] Yousry, S.M., Diaa, N., Shaheen, G.H., et al. (2016) The Interleukin-17F (7488T/C) Gene Polymorphism and the Risk of Chronic Immune Thrombocytopenic Purpura in Egyptian Patients. Egypt Journal of Laboratory Medicine, 21.

[32] Botros, S.K., Ibrahim, O.M. and Gad, A.A. (2018) Study of the Role of IL-17F Gene Polymorphism in the Development of Immune Thrombocytopenia among the Egyptian Children. Egyptian Journal of Medical Human Genetics. https://doi.org/10.1016/j.ejmhg.2018.02.003

[33] Murphy, C.A., Langrish, C.L., Chen, Y., et al. (2003) Divergent Pro- and Anti-Inflammatory Roles for IL-23 and IL-12 in Joint Autoimmune Inflammation. Journal of Experimental Medicine, 198, 1951-1957.

https://doi.org/10.1084/jem.20030896

[34] Najafi, S., Hadinedoushan, H., Eslami, G., et al. (2014) Association of IL-17A and IL-17 F Gene Polymorphisms with Recurrent Pregnancy Loss in Iranian Women. Journal of Assisted Reproduction and Genetics, 31, 1491-1496.

https://doi.org/10.1007/s10815-014-0294-0 